\title{
Potential of Global Health Education in Low-Income
}

\section{Settings}

\author{
Karmacharya BM \\ Dhulikhel Hospital \\ Kathmandu University Hospital, Dhulikhel, Kavre, Nepal
}

Global Health $(\mathrm{GH})$ as a discipline emerged mainly in the last decade and is still a developing subject. Koplan et al. defined GH as 'an area for study, research, and practice that places a priority on improving health and achieving health equity for all people world-wide.' ${ }^{1}$ Kickbushtermed it as 'those health issues that transcend national boundaries and governments and call for actions on the global forces that determine the health of people'. ${ }^{2}$ Beaglehole et al. suggested that $\mathrm{GH}$ is collaborative trans-national research and action for promoting health for all. ${ }^{3}$ There is yet to be a consensus on GH definition and many in fact argue that there is no major difference between $\mathrm{GH}$ and public health. ${ }^{4}$ However, the rise of institutions teaching $\mathrm{GH}$ as a formal academic degree is a testimony to the fact that although debated, the concept of $\mathrm{GH}$ is rapidly gaining a strong ground worldwide. International peer-reviewed journals dedicated specifically for GH have emerged in the past few years, giving further momentum to this field.

Some of the essential elements of GH lie in the realization that health issues in the current context transcend the boundaries of nations; equity is an important parameter for assessing programs in health; and it is difficult to achieve successful outcomes in health programs without an extensive inter-disciplinary and multidisciplinary approach. ${ }^{1}$ It is very likely that in coming years this concept will steadily grow and will be accepted as one of the core elements of health sciences education and research worldwide.

An important aspect of the GH concept is that the experience on various health issues from different nations and contexts can have valuable academic and training significance. Since major global health issues include more about the topics in low-income settings, it is paradoxical that most centers dedicated for GH training and education are located in high-income countries. ${ }^{3}$ Solutions to the problems can be best explored and identified in places where the problems exist. It is thus logical to assume that the unique sets of challenges in health problems faced in low-income settings and the successes (or failures) of innovative approaches to address those would be relevant to similar settings around the world. If structured academic or training programs are developed around the problems and activities in such low-income settings, participants interested in GH can have very enriching experience. Countries like Nepal that spearheaded numerous daring initiatives in GH-related issues (mainly maternal and child health), can thus be valuable sites for GH education.Through its Global Health Program, Dhulikhel Hospital Kathmandu University Hospital started organizing short-term courses on GH for international students since 2009 in collaboration with international partner universities. Experience from programs like this can be valuable for other low-income institutions considering initiating programs in $\mathrm{GH}$.

Rather than focusing much on the general conceptual aspects of $\mathrm{GH}$, which do not specifically require particular settings for teaching, GH courses in low-income settings can be best utilized if specific health topics and the approaches undertaken in such settings can be emphasized so that the participants can get a closer, first hand understanding of the issues. For example, in the context of GH courses in Nepal, it is probably more rewarding to have detail activities in giving the participants an understanding of the Female Community Health Volunteers program of Nepal rather than spending lots of sessions teaching GH issues in relation to maternal and child health. In the same way, a thorough discussion on Nepalese experience of tuberculosis control program coupled with a visit to a Directly Observed Treatment facility would be more useful to the participants rather than just highlighting on the global challenges in relation to tuberculosis treatment and control.

There are also lots of opportunities to get professionals from other disciplines involved in the health programs and assimilate that experience to incorporate in $\mathrm{GH}$ courses. The multi and inter disciplinary aspects of $\mathrm{GH}$ are some of the least explored and least understood aspects. Hence, any experience in this context can be very valuable. For example, it would be interesting to see how professionals from environmental science, public health and mechanical engineering can work together to help establish model programs on improved smokeless cooking stoves in rural Nepal. This experience can mean a lot to other communities in the world 
that suffer from similar health hazards of indoor house smoke.

Besides the structured courses, GH-related student and/or faculty-led research projects and also clerkships and internships can be established with similar approaches. Generally, existing institutional collaborations are good partners to start GH courses with. However, one might also consider proactive searching and approaching for institutions that might be interested in co-organizing or participating in such programs.

It is thus important to understand the possibilities that are present among the health institutions of low-income settings in participating and taking the lead in GH education. Besides others, it requires a paradigm shift in the attitude towards the potential role of such institutions in transforming the health care scenario around the world. In addition to an enriching discourse on global aspects of health care, involvement in $\mathrm{GH}$ coursesalso presents an opportunity to critically assess and improve current health care approaches. It also makes us realize that what we practice and learn in our settings might someday change lives of people far beyond our imagination and reach. That is definitely a motivation not worth ignoring.

\section{REFERENCES}

1. Koplan JP, Bond TC, Merson MH, Reddy KS, Rodriguez MH, Sewankambo N.K et.al. Consortium of Universities for Global Health Executive Board. Towards a common definition of global health. Lancet. 2009; 373(9679):1993-1995.

2. Kickbush I. The need for a European strategy on global health. Scandinavian Journal of Public Health. 2006; 34(6), 34(6):561-565.

3. Beaglehole R, Bonita R. What is global health? Global Health Action. $2010 ; 3: 5142$.

4. Fried LP, Bentley ME, Buekens P, Burke DS, Frenk JJ, Klag MJ, et al. Global Health is public health. Lancet. 2010; 375: 535-7. 